\title{
ANALYSIS MUSIC CONCERTS ADOPTING THE MATHEMATICAL MODEL OF HIT PHENOMENA
}

\author{
Kawahata Yasuko $^{1}$, Genda Etsuo ${ }^{1}$, and Ishii Akira ${ }^{2}$ \\ ${ }^{1}$ Department of Contents and Creative Design, Graduate School of Design, \\ Kyushu University Hakozaki, Higashi-ku, Fukuoka,Japan \\ 3DS12011W@s.kyushu-u.ac.jp \\ ${ }^{2}$ Department of Applied Mathematics and Physics Tottori University \\ Koyama, Tottori, Japan \\ ishii@damp.tottori-u.ac.jp
}

\begin{abstract}
A mathematical model for the hit phenomenon in entertainment within a society is presented as a stochastic process of interactions of human dynamics. In this paper, we analyzed music to the concert.Knowing the cost of advertising the concert is difficult. But exposure to the media of the artist can be seen. We tried to analysis of music concert itself by performing a prediction of reputation of artists during the concert tour from this exposure.In this paper, The world most popular rock band Coldplay is analyzed using the SNS data. L'Arc-en-Ciel of Japanese rock band and LADYGAGA are also analyzed using the data of SNS as well.
\end{abstract}

\section{KEYWORDS}

Hitphenomena, Advertisement, Music concert, WOM, Twitter, Coldplay, LADYGAGA, L'Arcen-Ciel

\section{INTRODUCTION}

The popularity of entertainment event by using the change of the day for each of the number of SNS posting, "the mathematical theory for hit phenomena" has been presented[1-3]. Our model was originally designed to predict how word-of-mouth communication spread over social networks or in the real society, applying it to conversations about movies in particular, which was a success. Moreover, we also found that when they overlapped their predictions with the actual revenue of the films, they were very similar. In the model [2], the key factors to affect the mind of the consumers are three: advertisement effects, the word-of-mouth(WOM) effects and the rumour effects. Recognising that WOM communication, as well as advertising, has a profound effect on whether a person goes to see a movie or not, whether this is talking about it to friends (direct communication or WOM) or overhearing a conversation about it in a café(indirect communication or the rumour), we accounted for this in our calculations. The difference between our theory and the previously presented researches [4-19] are discussed in Ref.1.In this paper, we analyzed music to the concert. If an entertainersor concerts is really very excellent, the number of SNS posting does not decrease rapidly after a certain his/her event and their news. In addition there may be differences in the reaction depending on the type of SNS to use of people. Knowing the cost of advertising the concert is difficult. But exposure to the media of the artist can be seen.

Natarajan Meghanathan et al. (Eds) : ITCSE, ICDIP, ICAIT - 2013

pp. 43-51, 2013. (C) CS \& IT-CSCP 2013

DOI : 10.5121/csit.2013.3905 
We tried to analysis of music concert itself by performing a prediction of reputation of artists during the concert tour from this exposure. In this paper,we show that the mathematical model of the hit phenomenonis also applicable to the prediction reputation of musicians in the (Englishspeaking) world, the box office of the concert. Coldplay is a rock band that got the attendance most in 2012.We analyzed using the data of SNS (TOPSY PRO) the LADYGAGA has gained followers most Twitter in 2011 and Also from Japan, we analyzed the L'Arc-en-Ciel of rock band that made the Madison Square Garden concert for the first time in Japanese in 2012. The method of the study, we were selected from Tourintel the box office of artists to target first. Then we were compared at the same time ranking of the followers of Twitter. We chose the time and the artists that target from among them. In addition, we investigated the media exposure of artists that target. Performs prediction by the mathematical model based on the media exposure, and compared with the WOM.

\section{MATHEMATiCAL ThEORY FOR Hit PHENOMENA}

\subsection{Intention of each person for enjoying entertainment}

In this model, the communication with friends is considered as direct communication or two-body interaction. The rumor in societies is considered as indirect communication or three-body interaction. In this model, we define the intention for person " $i$ " in the society to entertainment activities as $I_{i}(t)$. the model can describe the intention of each person for enjoying entertainment as the equation of the intention of person $i$ with two-body interaction and three-body interaction terms.

According to the Ref. 1, we write down the equation of the intention at the individual level as

$$
\frac{d I_{i}(t)}{d t}=-a I_{i}(t)+\sum_{j} d_{i j} I_{j}(t)+\sum_{j} \sum_{k} h_{i k} d_{j \mu} I_{j}(t) I_{k}(t)+f_{i}(t)
$$

where $d_{i j}, h_{i j k}$, and $f_{i}(t)$ are the coefficient of the direct communication, the coefficient of the indirect communication, and the random effect for person $i$, respectively. We consider the above equation for every person in the society so that $i=1, \mathrm{~N}_{\mathrm{p}}$ where $N_{y}$, is the effective population of the society for a certain entertainment. The advertisement and publicity effect for each person can be described as the random effect $f_{i}(t)$.

Eq. (1) is the equation for all individual persons, but it is not convenient for analysis. Thus, we consider here the ensemble average of the intention of individual persons as follows:

$$
\langle I(t)\rangle=\frac{1}{N} \sum_{i} I_{i}(t)
$$

Taking the ensemble average of Eq. (1), we obtain for the left-hand side:

$$
\left\langle\frac{d I_{i}(t)}{d t}\right\rangle=\frac{1}{N} \sum_{i} \frac{d I_{i}(t)}{d t}=\frac{d}{d t}\left(\frac{1}{N} \sum_{i} I_{i}(t)\right)=\frac{d\langle(I\rangle}{d t}
$$

For the right-hand side, the ensemble average of the first, second, and third is as follows: 


$$
\begin{aligned}
& \left\langle-a I_{i}\right\rangle=-a \frac{1}{N} \sum_{i} I_{i}(t)=-a\langle I(t)\rangle \\
& \left\langle\sum_{J} d_{j} I_{L}(t)\right\rangle=\left\langle\sum_{J} d \mathbb{I}_{J}(t)\right\rangle=\frac{1}{N} \sum_{i} \sum_{J} d \mathbb{I}_{J}(t)=\sum_{i} d \frac{1}{N} \sum_{J} I_{J}(t)=N d\langle I(t)\rangle \\
& \left\langle\sum_{i} \sum_{k} p_{t k} I_{i}(t) I_{k}(t)\right\rangle=\left\langle p \sum_{i} \sum_{k} I_{i}(t) I_{k}(t)\right\rangle \\
& =\frac{1}{N} \sum_{t} p \sum_{i} \sum_{k} I_{i}(t) I_{k}(t) \\
& =\sum_{i} p \frac{1}{N} \sum_{j} \sum_{k} I_{i}(t) I_{k}(t) \\
& =N p \sum_{t} \frac{1}{N} \sum_{i} I_{i}(t) \frac{1}{N} \sum_{k} I_{k}(t) \\
& =N^{2} p\langle I(t)\}^{2}
\end{aligned}
$$

where we assume that the coefficient of the direct and indirect communications can be approximated to be under the ensemble average.

For the fourth term of Eq. (1), the random effect term, we consider that the random effect can be divided into two parts: the collective effect and the individual effect:

$$
\left\langle f_{i}(t)\right\rangle=\frac{1}{N} \sum_{i} f_{i}(t)=\langle f(t)\rangle
$$

where sfory means the deviation of the individual external effects from the collective effect,

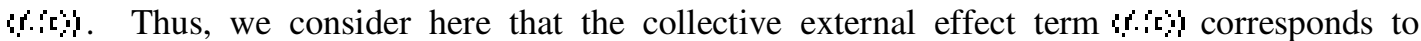
advertisements and publicity to persons in the society. The deviation term st. is corresponds to the deviation effect from the collective advertisement and publicity effect for individual persons, which we can assume to be

$$
\left\langle\Delta f_{i}(t)\right\rangle=\frac{1}{N} \sum_{i} \Delta f_{i}(t)=0
$$

Therefore, we obtain the equation for the ensemble-averaged intention to entertainment in the following manner as shown in Ref.1:

$$
\frac{d\langle I(t)\rangle}{d t}=-a\langle I(t)\rangle+D\langle I(t)\rangle+P\langle I(t)\rangle^{2}+\langle f(t)\rangle
$$

Eq. (10) can be applied to the intention in the real entertainment market. For the calculations of box office

movie in Ref.1, Eq. (10) should be solved in the way of Ref. 1 that the watched persons and unwatched persons are treated separately. For the examples of this paper, such effect can be neglected. In this paper, we have the media exposure of the daily value of the input. Therefore, we did not adapt this time the expression of decay, such as adapted to the hit phenomenon in the box office. 


\subsection{Concerts and Advertisement}

We were with the advertising costs for input in mathematical models of the past.But this time, we adapted the following equation because you are media exposure of the daily input.Concerts and Advertisement are the very important factor to increase the intention of each person for enjoying entertainment. Concerts and Advertisement are done at Concerts Hall, Live House, TV, newspaper and other media. We consider the advertisement effect as an external force term $\mathrm{A}(\mathrm{t})$ to the intention as follows,

$$
\frac{d l_{i}}{d t}=C_{a d v} A(t)+\sum_{j} D_{i j} I_{j}(t)+\sum_{j} \sum_{k} P_{i j k} I_{j}(t) I_{k}(t)
$$

where $D_{i j}$ is the factor for the direct communication and $P_{i j k}$ is the factor for the indirect communication. The factor Cadv corresponds to the strength of the impression of the media or Concerts exposure for each advertising campaign. Because of the term of the indirect communication, this equation is a nonlinear equation. If we consider Concerts and Advertisement, we can solve the equation by including several effect of the advertisement in the following way,

$$
C_{a d v} A(t) \Rightarrow \sum_{i} C_{i} A_{i}(t)
$$

where each coefficient $\mathrm{C}_{\mathrm{i}}$ corresponds to the each advertisement and Concert's counts and can be determined by using the random number technique introduced in Ref. [1]. The actual formula used in the calculation to analyse the SNS response are introduced in detail in Ref.[1].

\section{RESULTS}

\subsection{Box Office Concerts}

Here, we show the results for box office concerts of Coldplay [21]. In figure 1,2, we show the daily number of Event(Concert), the ticket sold and the words of mouth (WOM) for Coldplay in 2012. We measured the number of write topic of Twitter and blog about artists using the Topsy[22]. And we used the value tour box office costs through Box office score data of (attendance)[20]. The result show us that the daily number of WOM seems to be influenced by the event of each days. For the ticket sold, we found a kind of threshold or switch-on at the day of the first high peak of WOM. Thus, the daily ticket sold data shows correlation with daily WOM data, though the correlation is not perfect like the box office business for motion picture shown in Ref.3. In particular, there is a correlation with the WOM data rate rise and peak of the sales of the daily ticket sold data. 2012/05/05, The 20th Annual KROQ Weenie Roast Y Fiesta broadcasted live from Webcast. Becausef this ticket for the concert sold out.And Coldplay performed to tribute to Beastie Boy Adam Yauch at this concert. Thus, WOM data on this day would have shown a significant peak.[21-26] 


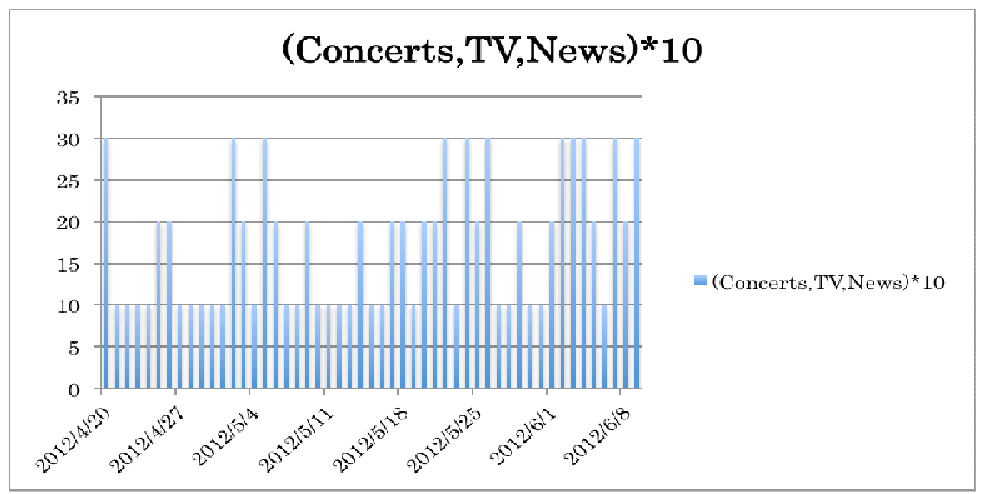

Figure 1. The number of Concerts and TV and News for Coldplay [22-24].

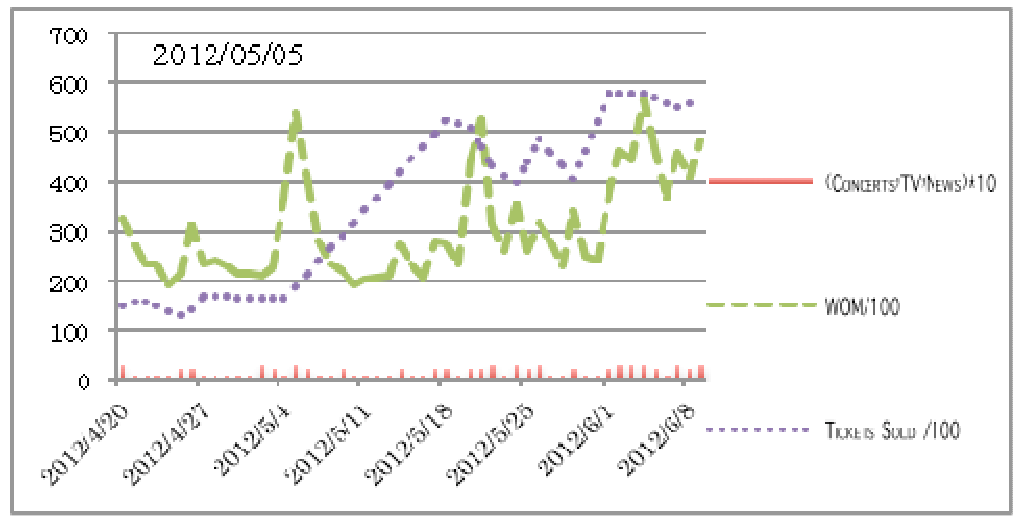

Figure 2. Observed ticket sold, WOM and the number of Concerts and TV and News for Coldplay, got the attendance most in 2012[20,22].

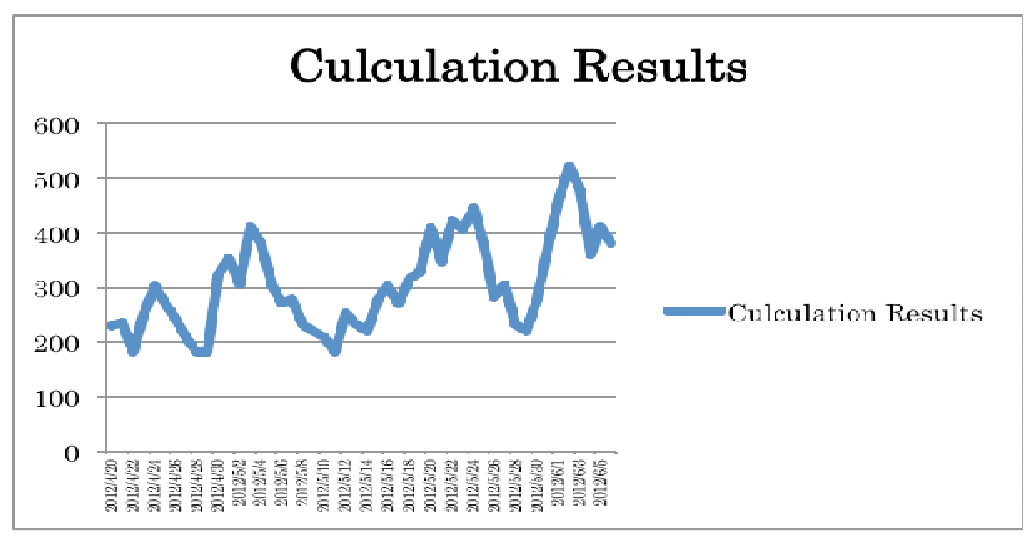

Figure 3. The calculation and the observed data for Coldplay, the British rock band. 


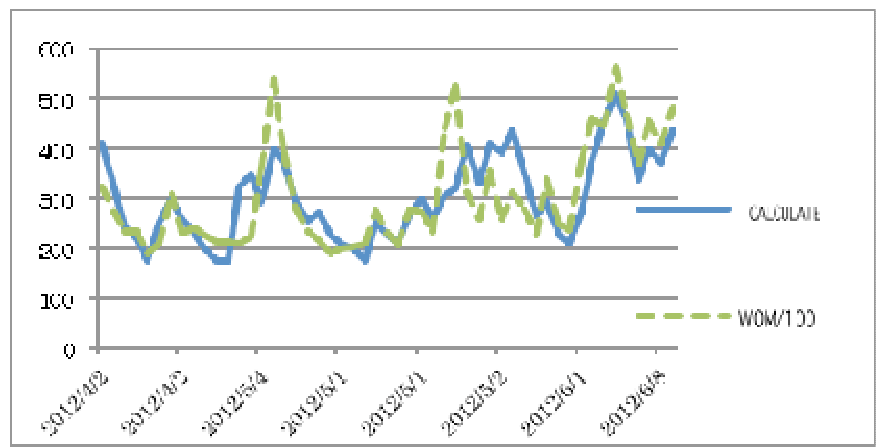

Figure 4. The calculation and the observed data for Coldplay, the British rock band. The line means the observed number of daily posting of WOM(Twitter)/100(Green) and Calculate(Blue).

Using Eq. (10) with the daily number of event of the Coldplay as the influence of the advertisement effect $\langle f(t)\rangle$, we obtain the following result in Figure 2. We found in Figure 2 that our calculation of the intention to entertainment for Coldplay shows very well agreement with the real observed WOM.

\subsection{Similar Calculation}

The similar calculations are showed in Figure.5 and 6 for LADY GAGA and L'Arc-enCiel,respectively. LADY GAGA is the very famous and popular female singer.[27,28] L'Arc-enCiel is a Japanese rock band that was founded in 1991 in Osaka. [29]We thought worthy as the target period for measuring the topic of LADY GAGA the world because there was a chance of TV appearances. In other words, We're easy to collect quantitatively the WOM data generated in the TV appearances and concerts LADYGAGA around the world by choosing this time. In addition, in May 2011, the number of Twitter followers has become the world is LADYGAGA, the number was more than 11 million people. [31]

From this point of view, LADYGAGA of May 2011 was a case suitable to analyze and predict the reputation around the world for artists. In Figure. 5, we conducted a measurement of L'Arcen-Ciel to have succeeded the Madison Square Garden concert for the first time in the Japanese performed in parallel overseas tour and domestic tour in 2012.

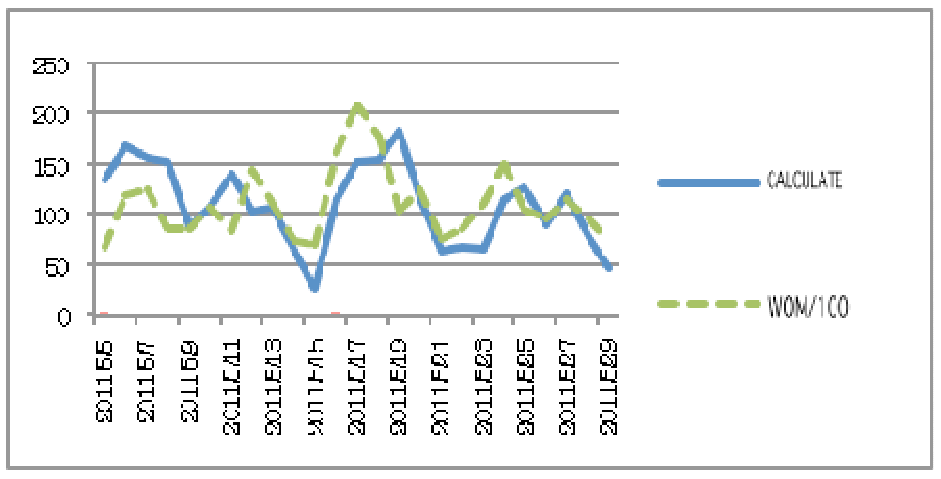

Figure 5. LADY GAGA Result of calculation 


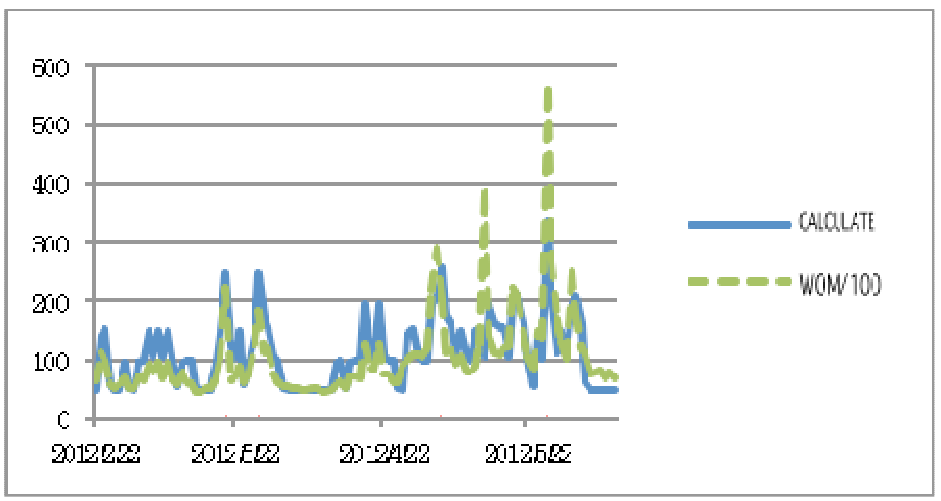

Figure 6. L'Arc-en-Ciel Result of calculation

\section{DISCUSSION}

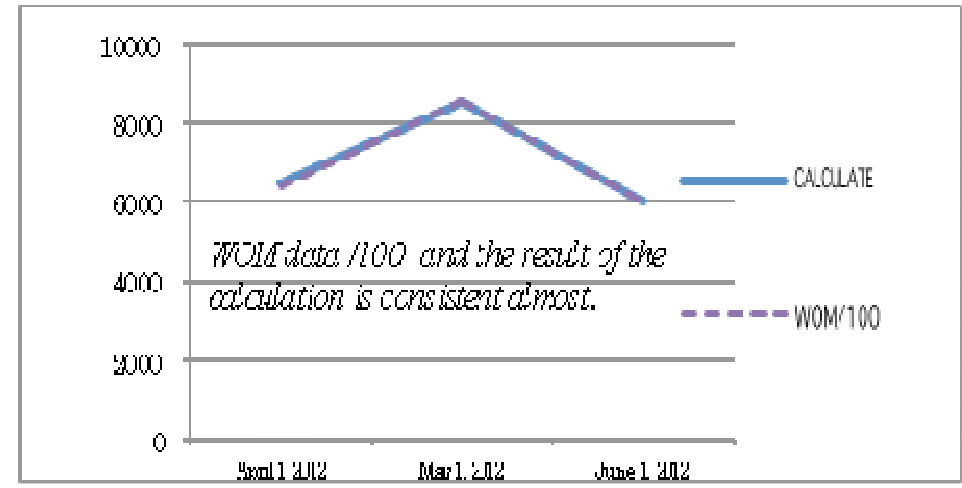

Figure 7. Coldplay Result of monthly calculation

Table I

Table of parameters for the Coldplay. Cadv is the strength of the advertisement; a is the decline factor of the advertisement; Dnn is the direct communication factor; Pnn is the indirect communication factor.

\begin{tabular}{|ll|}
\hline Cadv & 47.20 \\
\hline $\mathrm{a}$ & $21.12(1 /$ day $)$ \\
\hline NpDnn & $0.00050(1 /$ day $)$ \\
\hline & \\
Np2Pnn & $0.00050 e^{-1 / 4}(1 /$ day $)$ \\
\hline
\end{tabular}

From Figures 1-6 and Table I,II we found that our simulation can reproduce the daily and monthly counts of tickets sold to music concerts. In other words, the simulation can reproduce the same counts of reputation ofthe artists $[43,44]$. 
Table II

Table of parameters for the Coldplay. Cadv is the strength of the advertisement; a is the decline factor of the advertisement; Dnn is the direct communication factor; Pnn is the indirect communication factor.

\begin{tabular}{|ll|}
\hline Cadv & 15.95 \\
\hline a & $14.91(1 /$ month $)$ \\
\hline NpDnn & $0.0000748(1 /$ month $)$ \\
\hline Np2Pnn & $0.0000128(1 /$ month $)$ \\
\hline
\end{tabular}

As we found in the figures and tabeles our calculations using Eq. (10) agree very well with the observed daily WOM data. Therefore, we can consider that the mathematical model for hit phenomena using Eq. (10) can be applied also for the music entertainment. [1-3].

\section{CONCLUSION}

We apply the mathematical theory for revenue prediction of music concerts using the mathematical Model of hit phenomena and The calculation using our mathematical model for hit phenomena presents the intention to entertainment in the society. Residual problem is the difference in the nature of the fan in the WOM data. For example, there will be regional differences and differences in the climax of the topic to be born from the feature of the SNS. We also are required analysis and quantified by the extension of this method as well as the relationship of the media reaction and the nature of the fan is generated. And we must verify the proposed method is valid from the correlation with CD sales and concert tickets with WOM data and reputation in the world of artists in the region. Thus, we will require more consideration to this matter. The outlook for the future, we want to measure the mathematical model of trends in relation to the concert artists and advertising in real time actually. It is expected to target the artists active in Japan and Asia actually.

\section{ACKNOWLEDGEMENTS}

The authors would like to thank CEO Uchiyama Kouki of Hotlink, CEO Koguchi Hidehiko of Perspective Media , Theatre TinkerBell for giving them Database and helpful discussions. Great creaters who have supported the motivation of this study, We also thank versity KANSEI center for Arts and Science, ADAA (Asia Digital Arts Awards ) which gives the best environment to do their studies in particular, to carry out development activities creativity of Asia. In adidition, it is enormously grateful family and friends and Genda Lab. Members, also ancestors who have supported much emotional support. Y.Kawahata also thanks the Japan Student Services Organization for the scholarship.

\section{REFERENCES}

[1] Akira Ishii, H. Arakaki, N. Matsuda, S. Umemura, T. Urushidani, N. Yamagata, and N. Yoshida,(2012) "The 'Hit'phenomenon: a mathematical model of human dynamics interactions as a stochastic process," New Journal of Physics, vol. 14, pp. 063018.

[2] Akira Ishiil, Sho Ota, Hideo Koguchi and Koki Uchiyama,(2013) "Quantitative analysis of social popularity for Japanase pop girl group AKB48 using mathematical model for hit phenomena" ICBAKE2013 unpublished.

[3] A Ishii, K Furuta, T Oka, H Koguchi and K Uchiyama, (2013) "Mathematical Model of Hit Phenomena as a theory for collective motion of human mind in societies, " the Frontiers of Artificial Intelligence and Applications (FAIA) series (IOS Press) in press. 
[4] Samuel Bredl,(2012)" How the US government is monitoring Social Media,"Digital Communications and Privacy, V200604, pp.36.

[5] Bogers, T., \& Björneborn, L. (2013)"Micro-serendipity: Meaningful coincidences in everyday life shared on Twitter,"iConference Proceedings.pp.196-208.

[6] Thaiprayoon, S. Kongthon, A ; Palingoon, P.(2012) ; Haruechaiyasak, C. "Search result clustering for Thai Twitter based on Suffix Tree Clustering,"Electrical Engineering/ Electronics, Computer, Telecommunications and Information Technology (ECTI-CON), 2012 9th International Conference on (May16-18 2012),pp.1-4.

[7] Adrian Irshadi Siregar, Budi Permadi Iskandar"Measuring the Effectiveness of XL Axiata's Twitter Account in Handling Customers Complaints,(2011), "Journal of Business and Management,vol.1,5.

[8] Goel S, Hofman J M, Lahaie S, Pennock D M, and Watts D J, (2010)" Predicting Consumer Behavior with Web Search," PNAS,vol.107, pp.17486-17490.

[9] Karniouchina EV, (2011)"Impact of star and movie buzz on motion picture distribution and box office revenue, "International Journal of Research in Marketing vol.28, pp.62-74.

[10] Sinha S and Raghavendra S, (2004)"Hollywood blockbusters and long-tailed distributions: An empirical study of the popularity of movies, "Eur. Phys. J. B42, pp.293-296.

[11] Pan R K and Sinha S,(2010) "The statistical laws of popularity: universal properties of the box-office dynamics of motion pictures, "New Journal of Physics, vol.12, pp.115004.

[12] Asur S and Huberman R A,(2010) "Predicting the Future with Social Media, "Computers and Society Physics and Society,pp.492-499.

[13] Ratkiewicz J, Fortunato S, Flammini A, Menczer F, and Vespignani A, (2010)"Characterizing and Modeling the Dynamics of Online Popularity, "Phys.Rev.Lett.vol.105, pp. 158701-158704.

[14] Eliashberg, J. Jonker, J. J. Sawhney, M. S. and Wierenga B,(2000) "MOVIEMOD: An Implementable DecisionSupport System for Prelaunch Evaluation of Motion Pictures, "Marketing Science, vol.19, pp.226-243.

[15] F.M.Bass,(1969) "A New Product Growth Model for Consumer Durables," Management Science, vol.15,pp.215-227.

[16] F.M.Bass,(1986) "The Adoption of a Marketing Model: Comments and Observations, "in Innovation Diffusion Models of New Product Acceptance, Mahajan V and Wind Y, eds., Ballinger.

[17] Dellarocas C, Awad NF, and Zhang X, (2004)"Strategic Manipulation of Internet Opinion Forums: Implications for Consumers and Firms, "2004 working paper, MIT Sloan School of Management, pp.38.

[18] Dellarocas C, Zhang X, and Awad NF J, (2007)"Exploring the value of online product reviews in forecasting sales, "The case of motion picturesInteractive Marketing,vol.21(4),pp.23-45 .

[19] Jim Farber"Osaka's L'arc-en-Ciel becomes first Japanese band to headline Madison Square Garden, "NEW YORK DAILY NEWS 2012-03-21 Retrieved.

[20] "TourIntel",Available at; http://www.tourintel.com/terms.html

[21] Bob Allen,Billboard Biz"Hot Tours: Coldplay Scores Massive Haul on World Tour, "2012-09-11 Retrieved.

[22] "Topsy", Available.at: http://topsy.com

[23] NME "Latest Coldplay News from NME.com, " Available.

[24] Coldplay, "Cold play news, "Available.at:http://www.coldplay.com/news.php

[25] "KROQ Weenie Roast Y Fiesta Webcast Details, Set Times, Venue Do's And Don'ts, And More , "2,May 2012. Retrieved.

[26] Sean Michaels "Coldplay perform tribute to Beastie Boys' Adam Yauch, " Guardian.co.uk, 8,May 2012. Retrieved.

[27] UNIVERSAL MUSIC "LADY GAGA NEWS, "2011-12-31 Retrieved.

[28] "Gagapedia Television appearances, "Retrieved.

[29] L'Arc-en-Ciel"L'Arc-en-Ciel news, "Retrieved.

[30] Natalie "L'Arc-en-Ciel news, " Retrieved.

[31] STAN SCHROEDER "Lady Gaga Hits 10 Million Twitter Followers," Mashble, 2011-05-17 Retrieved. 